\title{
Developing preservice elementary teachers' specialized content knowledge: the case of associative property
}

Meixia Ding

\begin{abstract}
Background: Specialized content knowledge (SCK) is a type of mathematical content knowledge specifically needed for teaching. This type of knowledge, although serving as a critical component for preservice teacher education, is often challenging to develop with preservice elementary teachers (PTs). The purpose of this study is to investigate PTs' development of SCK for teaching fundamental mathematical ideas in a university methods course. Focusing on the case of the associative property (AP) of multiplication, the author as the course instructor identified three instructional opportunities (a formal introduction and two delayed revisits) to stress two SCK components, representations, and explanations. PTs' learning progresses were assessed through three diagnostic tests (a pretest, a mid-term exam, and a final exam) and two prompts, which informed the upcoming lesson design. Meanwhile, the course instructor conducted ongoing reflections on PTs' learning, which also informed the corresponding lessons.

Results: It was found that PTs initially generated abstract number sentences without reasoning about the contexts of word problems. This representational sequence indicates a symbol precedence view. When prompted for explanations, PTs focused on individual numbers rather than quantitative relationships, and they could not consistently apply the basic meaning of multiplication for reasoning. The methods course, when designed to address these issues, promoted PTs' SCK development. At the end of the course, the majority of PTs were able to generate number sentences based on the word problem structures and provided reasonable explanations; however, the methods course also faced dilemmas due to PTs' robust symbol precedence view and the tension between PTs' learning and children's learning.

Conclusions: Very few studies have explored ways to support PTs' knowledge growth in SCK, especially for teaching fundamental mathematical ideas. This study, by carefully documenting the successes and challenges in developing PTs' SCK, contributes to the existing literature. Based on our findings, this study highlights the importance of stressing basic meanings so as to develop PTs' explanation skills. Meanwhile, to develop PTs' representation skills, university instructors should be aware of the tension between PTs' and children's learning as manifested by PTs' symbol precedence view. Finally, to support PTs' SCK growth, it is also important to emphasize the role of elementary textbooks.
\end{abstract}

Keywords: Preservice elementary teachers, Specialized content knowledge, Fundamental mathematical ideas, Associative property of multiplication, Methods course 


\section{Background}

Mathematics education programs should support preservice elementary teachers' (PTs) learning of specialized content knowledge (SCK), which is a type of mathematical content knowledge specifically needed for teaching (Ball et al. 2008). Such knowledge addresses both mathematics substance and pedagogical appropriateness. For example, in order to help elementary students make sense of abstract mathematical ideas such as the associative property (AP), a teacher may need to know how to illustrate AP through concrete word problem contexts. According to Morris et al. (2009), SCK is critical for teaching but often challenging to develop. This is because this type of knowledge focuses on unpacking a mathematical concept into its subcomponents to make it comprehensible for children. Thus, SCK does not rely on particular teaching contexts or particular students and therefore can be developed through university education programs. However, the acquisition of SCK demands PTs' well-connected mathematical knowledge and the awareness of children's learning, which is often found to be lacking in PT's existing conception (Borko et al. 1992; Ding et al. 2013; Morris and Hiebert 2009; Simon and Blume 1994). Such deficiency may be more problematic when developing PTs' SCK for teaching fundamental mathematical ideas (e.g., basic properties of operations) that are the core principles of mathematics but too abstract for children. As such, in order to better teach elementary children fundamental mathematical ideas, there is a need to investigate ways to support PTs development of SCK. The purpose of this study is to explore, through the case of the AP of multiplication, PTs' development of SCK and ways to support PTs' SCK development in a mathematics methods course. By documenting PTs' knowledge growth and the successes and challenges in learning to teach AP of multiplication, this study aims to contribute a small but vital piece to the knowledge base of teacher education (Morris et al. 2009), particularly in the area of teaching fundamental mathematical ideas.

\section{Literature review}

\section{Teaching fundamental mathematical ideas: the case of AP}

The associative property (AP) is a representative among fundamental mathematical ideas. This property, together with the commutative property $(\mathrm{CP})$, and distributive property (DP) are the basic laws of arithmetic, which can be learned in early grades and will lay a foundation for future learning of algebra such as solving equations. As such, researchers view these fundamental mathematical ideas as early algebra topics (Carpenter et al. 2003; Kaput et al. 2008). Due to the limited scope, this study will focus only on the AP of multiplication $(a b) c=a(b c)$, which is harder than AP of addition (Carpenter et al. 2003). The significance of the AP of multiplication warrants this focus. For instance, the Common Core State Standards (Common Core State Standards Initiative 2010) has clearly stressed that elementary students should learn and understand the AP of multiplication starting from the third grade. Ding et al. (2013) also reviewed several important aspects of this property. First, along with the other properties, the AP provides tremendous flexibility for computation (Bruner 1960). For instance, to compute $(3 \times 4) \times 25$, one may use the AP to first multiply the latter two numbers, $3 \times(4 \times 25)$, and obtain the answer quickly. Second, the AP of multiplication may serve as a powerful tool for justification, reasoning, and proof (Carpenter et al. 2003). The example given by Carpenter et al. was to prove the following mathematical statement, "when you multiply an even number times any whole number, you get an even number." One may use " $2 n$ " and " $m$ " to represent any even number and whole number, respectively, and then use the AP to obtain $(2 n) m=2(n m)$. Third, students' understanding of the AP may be transferred to later learning to solve algebraic equations and to learn more advanced concepts such as elementary group theory (Larsen 2010). Due to the significance of AP of multiplication, it is reasonable to expect PTs to obtain the necessary SCK for teaching this property through methods courses. Due to the fact that AP of multiplication is only one of the many fundamental mathematical ideas (e.g., CP, DP, inverse relations), findings from this study are also expected to serve as a window for developing PTs' SCK to teach other fundamental mathematical ideas.

Although fundamental mathematical ideas like the AP of multiplication are powerful, they are abstract in nature (Goldstone and Son 2005). Very often, students obtain only inert knowledge of these ideas (e.g., memorization of formulas) but lack the ability to flexibly retrieve them. For instance, when facing $(3 \times 4) \times 25$, a student may compute from the left to the right, $(3 \times 4) \times 25=12 \times 25$, without noticing the possibility of applying the AP. Such an inability to activate the AP is likely due to a lack of deep and meaningful initial learning (Chi and VanLehn 2012). In order to help students obtain meaningful initial learning, it is important for teachers (including PTs) to develop specialized content knowledge that will enable them to unpack an abstract concept in meaningful ways.

\section{Specialized content knowledge}

SCK is a key component of mathematical knowledge for teaching, a notion developed by Ball and colleagues (Ball et al. 2008) including common content knowledge (CCK), specialized content knowledge (SCK), knowledge of content and students (KCS), and knowledge of content and teaching (KCT). According to these researchers, SCK is a type of mathematical knowledge that is needed only for teaching rather than any other work. "This work 
involves an uncanny kind of unpacking of mathematics that is not needed-or even desirable-in settings other than teaching." (Ball et al. 2008, p. 400). SCK is different from CCK in that it is possessed by every educated adult; it is also different from KCS and KCT, which demand knowledge of specific students and teaching context. Therefore, SCK serves as a good candidate for topics to be covered in preservice teacher education (Morris et al. 2009). Note that although these knowledge components are distinguished in theory, they are not disjoint in actual teaching. For instance, SCK demands but also promotes CCK.

Even though Ball et al. (2008) provided a list of SCK tasks that are unique for teaching mathematics (e.g., "explaining mathematical goals and purposes to parents," "inspecting equivalencies," p. 400), this study focused mostly on teachers' representations and explanations, which are the core to unpacking a concept to make it visible and meaningful for students. Venkat (2015) argued that a focus on representations and explanations can simultaneously support teachers' mathematical learning and their learning about mathematics teaching. In fact, representations and explanations are not disjoint (e.g., one may explain the connections between representations). This study mainly stresses PTs' ability in (a) making connections between representations through a specific sequence, from concrete to abstract, and (b) explaining the meaning of an abstract number sentence by referring it to concrete contexts. As to be reviewed below, these two SCK components are largely emphasized by the existing literature, serving as a theoretical framework for this study.

Representations Ball et al. (2008) stressed teachers' ability in "selecting representations for particular purposes," "recognizing what is involved in using a particular representation," and "linking representations to underlying ideas and to other representations" (p. 400). Representations can be concrete (manipulatives, visual images, real-world contexts) or abstract (symbols). Both types of representations have strengths and limitations. For instance, concrete representations can activate students' personal experiences to aid sensemaking; however, these representations can contain irrelevant information that may hinder students from seeing the underlying mathematical ideas (Kaminski et al. 2008). Abstract representations support students' learning of powerful mathematical ideas; yet, these representations are often distant from students' personal experiences and thus may be learned in the form of inert knowledge. As such, it was suggested that teachers should help students make connections between concrete and abstract representations (National Mathematics Advisory Panel 2008; Pashler et al. 2007). Recent research particularly stresses a sequence of fading from concrete into abstract (also called "concreteness fading," Goldstone and Son 2005). This representational sequence is well aligned with how students learn and has been found to be effective in supporting both learning and transfer (Goldstone and Son 2005; McNeil and Fyfe 2012).

In this study, we expect PTs to illustrate fundamental ideas through word problem contexts. Thus, the representational sequence begins from concrete word problem situations. We consider word problems as concrete because the real-world situations provided by such problems "have the potential to offer memorable imagery that can act as a touchstone for teachers and learners in building and discussing abstract concepts" (Gerofsky 2009, p. 36). However, in order to make the underlying fundamental mathematical ideas explicit, we also expect that PTs will solve word problems symbolically, which can be generalized to reveal the underlying mathematical principle. The above sequence is consistent with a verbal precedence view (Nathan and Koedinger 2000) that emphasizes reasoning from verbal to symbol. This sequence is found well aligned with students' mathematical development (Koedinger and Nathan 2004; Nathan et al. 2002).

Explanations The second SCK component target in this study is explanation of mathematical ideas. Ball et al. (2008) highlighted tasks of "presenting mathematical ideas," "finding an example to make a specific mathematical point," and "giving or evaluating mathematical explanations" (p. 400). Prior studies have pointed out that students' self-explanations of mathematical ideas promote learning (Chi et al. 1994; Cobb 1994; Hiebert et al. 1997; Lewis 1988). However, in order to facilitate student explanations, teachers themselves should be able to explain. At times, teachers who are able to ask good question may not necessarily know the deep explanations to their own questions (Ding and Carlson 2013). Therefore, it is important to develop teachers' deep and meaningful explanations of a mathematical concept. According to Chi and VanLehn (2012), deep explanations refer to structural relationships rather than surface features or interactions among quantities rather than only individual numbers. Teachers whose explanations focus on structural relationships or quantitative interactions will likely have a better chance to develop students' selfexplanations of the target concepts and thus decreases the risk of rote memorization.

SCK for teaching AP of multiplication Based on the above SCK framework, we expect PTs to situate the teaching of AP of multiplication in word problem contexts, which can be unpacked through representation uses and explanations. Ding et al. (2012) reported that a widely used US textbook (Greenes et al. 2005) introduced AP through the following word problem 
"Mr. Levin's students are tasting foods grown in rainforests. He put 5 pieces of mango on each plate and put 2 plates on each table. There are 3 tables. How many pieces of mango are there?" (see Fig. 1). One may notice that the number choices in this problem do not effectively show the power of the AP as in the instance of $(3 \times 4) \times 25=$ $3 \times(4 \times 25)$; yet, for initial learning where the goal was to help student make sense of the AP, this mango problem context has a potential to serve the purpose. According to Ding et al., a teacher with SCK may first draw a diagram to represent the problem structure: 3 tables of 2 plates of 5 mangos (see Fig. 2). Such a diagram may serve as a mediating tool for classroom discussion and facilitate students' schema acquisition (Larkin and Simon 1987). Next, a teacher may guide students to reason by using the diagram to generate two mathematical solutions: $(3 \times 2) \times 5$ and $3 \times(2 \times 5)$. Finally, a teacher may guide students to compare two solutions to generate an instance of the AP, $(3 \times 2) \times 5=3 \times(2 \times 5)$, which may lead to further generalization of the algebraic formula, $(a b) c=a(b c)$. The above representational sequence-word problem, diagram, arithmetic solutions, and algebraic formula-indicates an inductive reasoning sequence, moving from concrete to abstract and from specific to general (see Fig. 2).

To ensure students' understanding of the numerical solutions, explanations should be incorporated so students could understand the meaning of these number sentences. For example, a teacher should help students understand why one multiplies certain numbers together (e.g., $3 \times 2$, $6 \times 5,2 \times 5,3 \times 10)$ and what each step actually meant. According to the problem structure, one may first find out how many plates are in total ( 3 tables of 2 plates thus $3 \times$ $2=6^{1}$ ) and then how many mangoes are in total ( 6 plates of 5 mangos thus $6 \times 5=30$ ), resulting in the first solution $(3 \times 2) \times 5$. Alternatively, one may first find out how many mangos are on one table ( 2 plates of 5 mangos thus $2 \times 5=$ $10)$ and then how many mangos are in total ( 3 tables of 10 mangos thus $3 \times 10=30$ ), resulting in the second solution, $3 \times(2 \times 5)$. The above explanations of the meaning of each step demands one's understanding of the quantitative definition of multiplication $a \times b$, which refers to " $a$ groups of $b$." This definition or the basic meaning of multiplication is the core in the multiplicative conceptual field serving as a foundation for mathematical reasoning (Beckmann and Izsák 2015; Beckmann et al. 2015). More importantly, this definition should be used consistently to enable the reasoning process (Beckmann et al. 2015). Consider, for example, if a teacher sometimes uses $3 \times 2$ to refer to 3 groups of 2 and then other times to refer to 2 groups of 3 , students will have difficulties constructing an understanding of multiplication and mathematics will become spurious and meaningless (Schwartz 2008). With a consistent use of the basic meaning, students will be

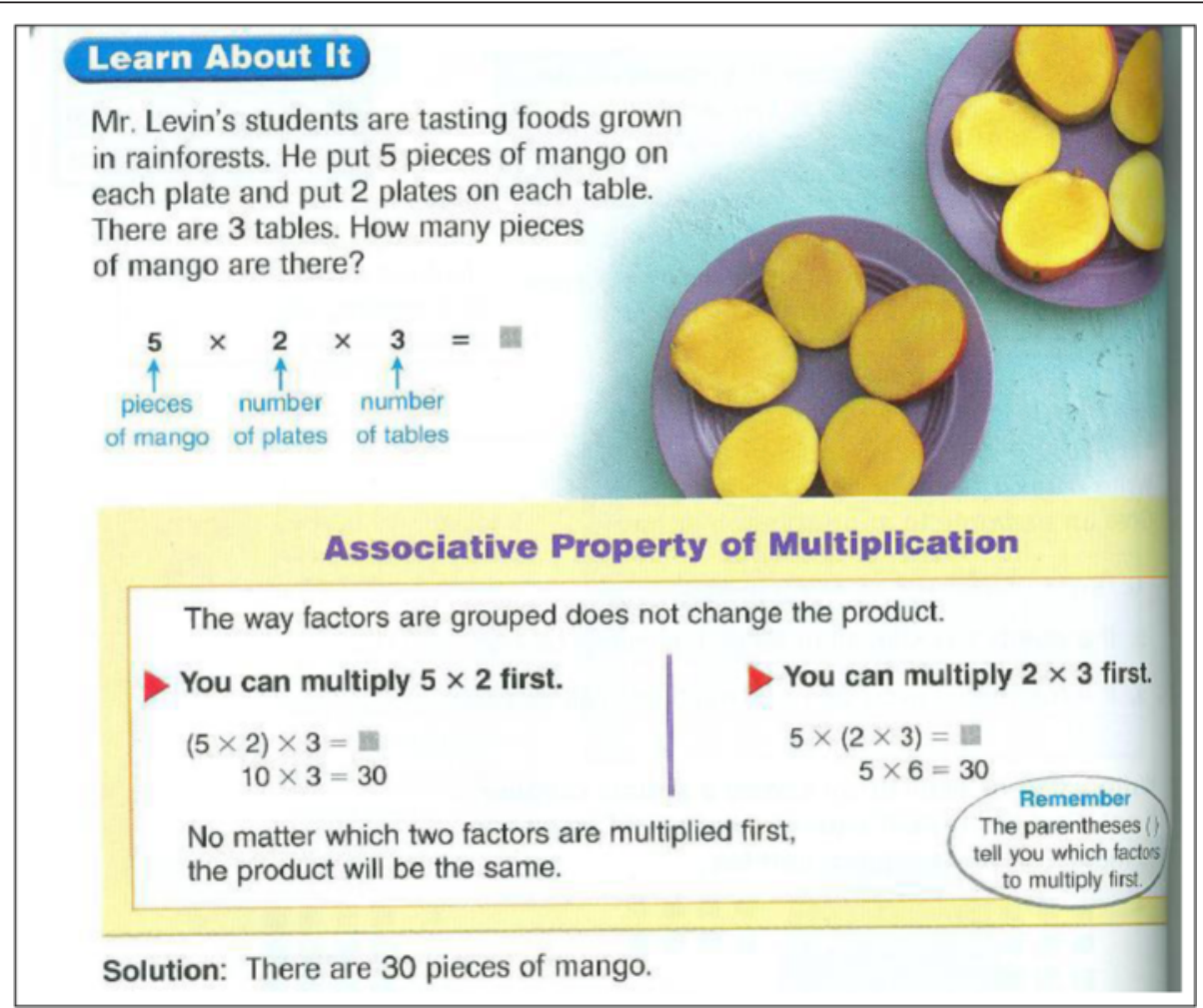

Fig. 1 The third grade elementary textbook page that presents the mango problem in Houghton Mifflin (Greenes et al. 2005) 


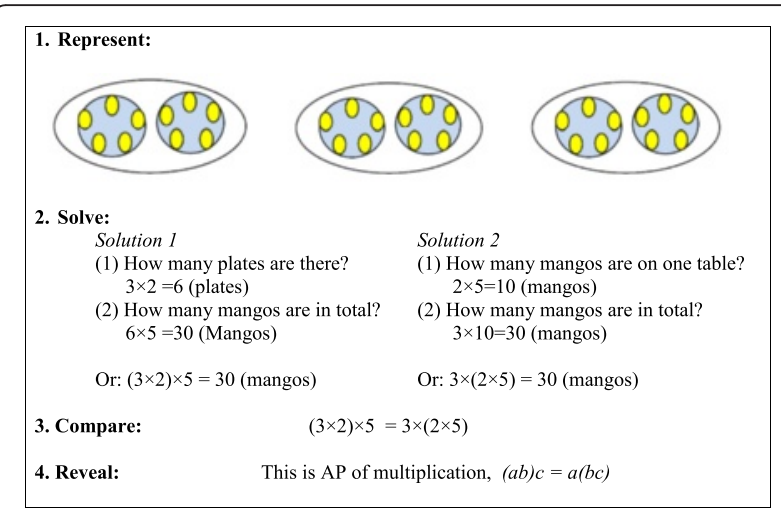

Fig. 2 The suggested teaching approach in Ding et al. (2012)

able to make inferences and link a number sentence back to the story problem situation to provide meaningful explanations.

\section{Developing PTs' SCK: the challenges}

PTs, as well as many other educated adults, possess compressed and abstract knowledge when they enter education programs. This type of knowledge, although demonstrating procedural fluency, is not sufficient for teaching children who need to construct knowledge based on their prior understanding. In particular with the AP of multiplication, Ding et al. (2013) reported that, when PTs first entered education programs, many of them did not remember the AP (CCK). For those who did remember, they had difficulties in illustrating the AP through concrete contexts (SCK). For instance, for a word problem with a structure of 3 groups of 2 groups of 4, many PTs generated number sentences such as $(3 \times 4) \times 2$, or $(4 \times 3) \times 2$, or $2 \times(3 \times 4)$. Although all these number sentences can produce a correct answer, they were not aligned with the word problem structure and each step cannot be explained in terms of the word problem situation. When prompted to explain these number sentences, PTs attended to the individual quantities (e.g., 3 boxes, 2 sets, 4 pencils) but not the interactions between them or the meaning of each step (e.g., 3 boxes of 2 sets thus $3 \times 2=6$ sets). These findings indicate PTs' procedural knowledge and their attention to number manipulation rather than quantitative relationships. In addition, many PTs directly presented the number sentences without reasoning upon the word problem situations (e.g., no pictures were drawn before presenting a number sentence). This finding echoes prior reports that US teachers (and textbooks) commonly possessed a symbol precedence view (as opposed to a verbal precedence view, Nathan and Koedinger 2000; Nathan et al. 2002). With this view, teachers and textbooks tended to treat manipulation with symbols as easier than word problems. Therefore, they often presented computations earlier than word problems because they thought word problems were too complex for students to learn. However, these researchers' experimental studies show that students indeed performed much better on word problems than the parallel algebraic equations, likely due to the fact that word problem contexts have elicited students personal knowledge to aid students' problem solving. Nathan and others' findings show that the commonly held symbol precedence view contradicts how students learn (Koedinger and Nathan 2004).

Prior findings on PTs' SCK for the AP of multiplication were consistent with a broader literature on PTs' learning to teach. Simon and Blume (1994) found that many PTs know the area formula "length $\times$ width," yet they could not explain why this formula worked through illustrations. Recently, Morris et al. (2009) found that PTs had incredible difficulty in unpacking decimal addition into sub-concepts that involve decimal units and the corresponding relations. These findings indicate the challenge to help PTs unpack their compressed knowledge. When getting frustrated, some PTs complained about these tasks as "the needlessly complicating things that should be straightforward" (Suzuka et al. 2010, p. 17). In fact, PTs who have taken methods courses may still not be able to unpack a task in ways that are comprehensible for children. As reported by Borko et al. (1992), when a student asked for the reasons of the inverse and multiply procedure for computing fraction division, a PT attempted to draw pictures to explain the process but failed to do so. This PT ended up telling students to just follow the procedure she provided. These findings call for a greater endeavor in developing PTs' SCK and a closer investigation of the role that university methods courses may play in supporting PTs' SCK development.

Prior research has shed light on this study; however, most of the SCK-related studies (e.g., Borko et al. 1992; Simon and Blume 1994; Morris and Hiebert 2009) have not explored the area of teaching fundamental mathematical ideas that undergird the mathematical system. Ding et al. (2013) did focus on SCK for teaching fundamental mathematical ideas and reported the levels of SCK PTs brought to teacher education; yet, this study did not investigate how PTs may be supported to grow this type of knowledge. Indeed, very few studies have tracked PTs' growth with SCK in university classrooms. The current study therefore aims to extend and continue this line of research. In particular, this research explores two questions: (1) How do PTs develop SCK for teaching the AP of multiplication through word problem contexts? and (2) How does the methods course instruction play a role in developing PTs' SCK?

\section{Methods}

This study employs a case study model (Stake 1995). The case in focus is PTs' learning to teach the AP of 
multiplication, which serves as a window that foreshadows the process of PTs' SCK development and the ways in which a methods course may support PTs' SCK development for teaching fundamental mathematical ideas.

\section{Participants}

This study was part of a methods course in a 4-year university in the USA. As the course instructor, the author conducted systemic reflections and improvements over a semester. Among the six course goals, one of them was to develop PTs' SCK for teaching fundamental mathematical ideas, which was discussed mainly through the case of teaching the AP of multiplication. It was expected that the intended SCK for teaching the AP of multiplication would help develop PTs' teaching schema and would enable them to teach other fundamental mathematical ideas such as $\mathrm{CP}, \mathrm{DP}$, and beyond. The current study documents the part of investigation with the AP of multiplication.

There were 25 PTs who took the methods course. This is the first but also the last course for PTs to learn to teach mathematics before they leave for elementary school jobs. Among these PTs, 24 PTs were female (96\%) and one was a male (4.0\%). All of the PTs were Caucasian. At the beginning of this course, the PTs were presented with an approved consent form and encouraged to participate in this study by providing permission for the instructor to use their coursework. It was also made clear that PTs' choices of participation would make no impact on their course grades. Supportively, all the PTs provided permission.

\section{Course design and procedures}

The course design contained at least three features. First, the instructor spaced the relevant learning over time (Pashler et al. 2007). As the mathematics methods course involves many topics, it is infeasible to spend too much time on the teaching of AP. However, since the targeted SCK is challenging to develop, it is also inappropriate to spend too little time on it. As such, the instructor spaced the learning across three existing curriculum opportunities. This included an initial math method lesson focused on the intended approach and two follow-up lessons arranged during the discussion of other topics. The second feature was to build the methods course instruction on the PTs' own learning. To understand PTs' learning processes, three diagnostics tests along with two prompts were administered, which informed the corresponding course instruction. In addition, the instructor conducted self-reflections on classroom instruction after each lesson. Finally, this methods course incorporated elementary textbook tasks into classroom discussions. This is because the method textbook (Reys et al. 2009) only briefly presented the definition, arithmetic examples, and the algebraic formula for the AP of multiplication, which targeted only the CCK but not SCK. To address this limitation, the instructor supplemented class discussion with the aforementioned mango problem (see Fig. 1). This mango task was selected from the third grade mathematics textbook of Houghton Mifflin (Greenes et al. 2005), a textbook series used by the participating PTs in their teaching practicum. Incorporating elementary textbook tasks into the methods course was recommended as an effective way to support PTs' learning and growth (Lloyd and Behm 2005). Indeed, incorporating elementary textbook tasks also made the methods course instruction more relevant to PTs' teaching practices. Figure 3 shows the procedures of data collection over the semester, which included three diagnostic tests, two prompts, and three methods course lessons.

As indicated by Fig. 3, a pretest using the mango problem (February 21) was conducted before lesson 1 (February 23). After lesson 1, PTs' SCK was reassessed through the mid-term exam (posttest 1, March 7). PTs' performance on both tests was suggested for comparison in prompt 1 (March 18), which informed lesson 2 (April 6) and lesson 3 (April 27). A second posttest was conducted through the final exam (posttest II, May 2), which contained prompt 2

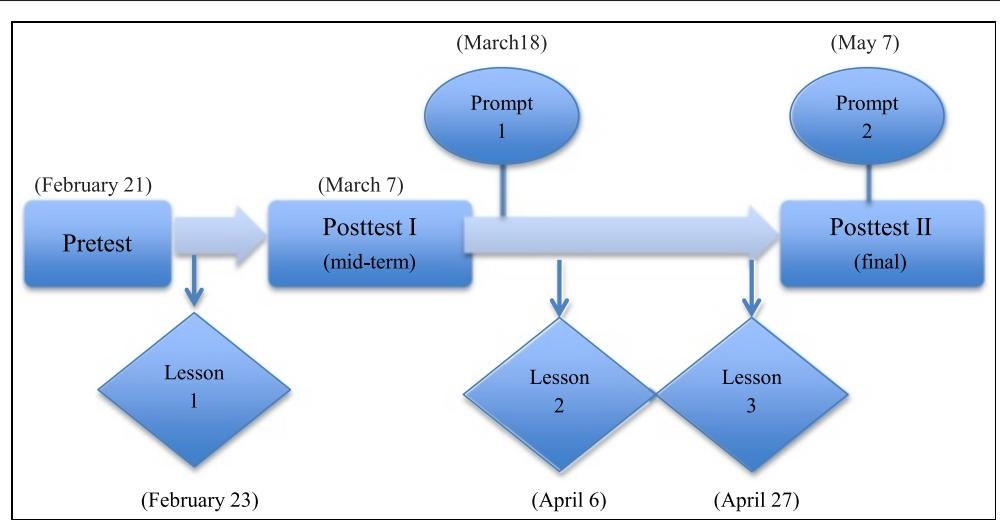

Fig. 3 Procedures of data collection over the semester 
requesting the PTs to reflect upon their overall learning progress.

\section{Data collection and data analysis}

The data presented in Fig. 3 were collected and analyzed to answer the two research questions. For question 1, the three diagnostic tests along with the two prompts were analyzed to identify PTs' knowledge changes. For the second research question, the three lessons were analyzed and compared with PTs' performance in the diagnostic tests and prompts so as to identify the role that the methods course instruction played in PTs' learning. Elaboration follows.

\section{Three diagnostic tests}

In all the diagnostic tests, the PTs were asked "How will you use the following word problem to teach the Associative Property of multiplication?" The word problems used in the tests were the mango, string, and cup tasks, respectively (see Table 1 ).

All these tasks demand PTs' SCK in that the PTs were expected to analyze the actual problem structures and solve them in ways that could help children make sense of the AP. These word problems shared the same problem structures (e.g., 3 tables of 2 plates of 5 mangos, 3 boxes of 2 sets of 4 strings, and 4 boxes of 3 cups of $\$ 5$, see Table 1). The mango and string problems also shared surface similarities, because the literal order of numbers in the problem situation (e.g., 4 strings- 2 sets- 3 boxes) was exactly opposite to the order in the problem structure (e.g., 3 boxes of 2 sets of 4 strings). The cup problem did not share the same problem structure, and its context also contained "money," which was a continuous quantity. The intention of using this cup problem was to measure students' transferability with a new context with a slightly different problem structure. Regardless of the differences in the surface features, all of these word problems should be unpacked in the same way as with the previously discussed mango problem (see Fig. 2).

It should be noted that the actual textbook presentation of the mango problem has shortcomings related to explanations and representations, respectively (see Fig. 1).
In terms of explanations, the textbook directly presented a two-step numerical solution, $5 \times 2 \times 3$, which could not be explained based on the problem structure, 3 tables of 2 plates of 5 mangos. For instance, the meaning of each step could not be explained by referring to the word problem situation (e.g., for " $5 \times 2$," one could not find 5 groups of 2 but 2 groups of 5). Moreover, the textbook only explained the literal meaning of each number (5 mangos, 2 plates, 3 tables). The second shortcoming is related to representations. The textbook directly introduced the AP and then applied it for computation whereas the mango problem was not used for sensemaking. This sequence indicated a symbol but not verbal precedence view (Nathan et al. 2002). Despite the shortcomings, this study deemed the mango problem a great learning opportunity to develop PTs' critical thinking skills and SCK for teaching fundamental mathematical ideas.

To analyze PT's knowledge change, PTs' responses to the mango, string, and cup problems were coded. We first coded whether a PT knew what the AP is (CCK). For example, if a PT provided a pair of solutions that switched numbers around [e.g., $(3 \times 2) \times 5$ and $(5 \times 3) \times 2$ ], we considered it as an indicator of lacking understanding of the AP of multiplication. We then coded the PTs' representations and explanations (SCK), which were detailed into the following aspects: (a) Does the PT draw a correct diagram to represent the problem structure? (b) Are the number sentences mathematically correct? (c) Are the explanations of each step meaningful? and (d) Does the solution sequence show a verbal precedence view? For each aspect, PTs' responses were coded using either " 1 " or " 0 " to indicate the presence of the knowledge component. All data were re-coded by the author 4 months later to check the reliability (96\%). A second coder was also trained to re-code $20 \%$ of PTs' responses with a coding reliability of $98 \%$. The mean score of each aspect in each exam was computed. Given the small sample size and categorical nature of this data, nonparametric tests were used for analysis. This included the use of the Friedman test to identify any differences between groups and the Wilcoxon test to identify changes over time (Leech et al. 2008; Nussbaum 2014). These tests indicated PTs' deficiency

Table 1 The tasks used in three diagnostic tests

\begin{tabular}{|c|c|c|c|c|c|}
\hline Exam & Name & Problem situation & $\begin{array}{l}\text { Problem } \\
\text { structure }\end{array}$ & Two solutions & Source \\
\hline Pretest & Mango & $\begin{array}{l}\text { Mr. Levin's students are tasting foods grown in rainforests. He } \\
\text { put } 5 \text { pieces of mango on each plate and put } 2 \text { plates on each } \\
\text { table. There are } 3 \text { tables. How many pieces of mango are there? }\end{array}$ & $\begin{array}{l}3 \text { tables of } \\
2 \text { plates of } \\
5 \text { mangos }\end{array}$ & $\begin{array}{l}(3 \times 2) \times 5= \\
3 \times(2 \times 5)\end{array}$ & $\begin{array}{l}\text { Houghton Mifflin- } \\
\text { 3rd grade }\end{array}$ \\
\hline $\begin{array}{l}\text { Posttest I } \\
\text { (mid-term exam) }\end{array}$ & String & $\begin{array}{l}\text { Upright bass strings come in sets of } 4 \text {. Suppose one box holds } \\
2 \text { sets of strings. If a musician orders } 3 \text { boxes, how many strings } \\
\text { will there be? }\end{array}$ & $\begin{array}{l}3 \text { boxes of } \\
2 \text { sets of } \\
4 \text { strings }\end{array}$ & $\begin{array}{l}(3 \times 2) \times 4= \\
3 \times(2 \times 4)\end{array}$ & $\begin{array}{l}\text { Houghton Mifflin- } \\
\text { 4th grade }\end{array}$ \\
\hline $\begin{array}{l}\text { Posttest II } \\
\text { (final exam) }\end{array}$ & Cup & $\begin{array}{l}\text { Each cup costs } \$ 5 \text {. Mom wants to purchase } 4 \text { boxes of cups } \\
\text { with each box holds } 3 \text { cups. How much does mom need to pay? }\end{array}$ & $\begin{array}{l}3 \text { cups of } \\
4 \text { boxes of } \$ 5\end{array}$ & $\begin{array}{l}(4 \times 3) \times 5= \\
4 \times(3 \times 5)\end{array}$ & $\begin{array}{l}\text { Chinese } 3 \text { rd grade } \\
\text { textbook (adapted) }\end{array}$ \\
\hline
\end{tabular}


in explanations and representational sequences. As such, PTs' responses to each of these aspects were further inspected and classified to identify the types of difficulties that the PTs had.

\section{Two prompts}

Along with the diagnostic tests, the PTs were asked to self-reflect on their performances. As previously mentioned, prompt 1 was conducted after the mid-term exam. The PTs were asked to compare their responses to the posttest 1 (string problem) and the pretest (mango problem), reporting the progress they made and the confusion that remained. Prompt 2 was part of the final exam. the PTs were asked to reflect, based on the cup problem, what they had learned about teaching fundamental mathematical ideas through word problems. Responses were coded to capture (a) PTs' insights on representations and explanations when unpacking a word problem to teach fundamental ideas and (b) PTs' remaining difficulties or their attitude changes.

\section{Three lessons}

To support PTs' learning to teach the AP, three lessons were spaced over the semester. By the time of lesson 1 , the instructor had read PTs' responses to the pretest and was aware of the PTs' difficulties in representations and explanations. Lesson 1 (75 $\mathrm{min})$ then formally discussed the mango problem using PTs' self-generated work. The purpose of using PTs' own work was to build on classroom instruction based on PTs' existing conceptions and engage them in course discussion. Lesson 2 reviewed AP in a chapter titled "Algebraic Thinking" (Reys et al. 2009) where the modeling perspective was involved. As one of the early algebra topics, it is appropriate to use $\mathrm{AP}$, along with $\mathrm{CP}$ and DP, as an example to show how these fundamental ideas can be illustrated. As part of this lesson, the PTs were asked to create a word problem for a given instance of AP, $(4 \times 3) \times 2=4 \times(3 \times 2)$. These students then modeled and solved the problems. The relevant discussion on AP in lesson 2 took about $30 \mathrm{~min}$. Lesson 3 was a final review of the course and thus was mostly open-ended. To revisit the course goals of teaching fundamental mathematical ideas, AP of multiplication was reviewed. PTs in small groups were asked to create a word problem that can be used to illustrate AP. The created problems were then exchanged among groups for peer solutions. This activity took approximately $20 \mathrm{~min}$. In all three lessons, PTs' representations and explanations were the targets of class discussion.

To identify how the methods course may have played a role in PTs' learning, all relevant instruction in three lessons were audio-recorded, transcribed, and analyzed in a qualitative manner. Each lesson was first segmented into small chunks, which was analyzed from the aspects of representations and explanations. After this, relevant excerpts were compared in terms of PTs' representation uses and explanations, respectively. Meanwhile, these excerpts were linked back to three diagnostic tests and two prompts so as to confirm PTs' SCK changes and explain how classroom instruction may have supported or failed to support PTs' knowledge growth. For instance, if there was a shift of PTs' explanations or representations between two diagnostic tests, the author went back to the lesson that occurred between the two tests (see Fig. 3) to identify the typical instructional moves that might have made an impact on PTs' learning. If there was no change in PTs' SCK between the diagnostic tests, the author also examined the corresponding lesson to understand why it failed to promote SCK changes. The next section reports findings for each research question.

\section{Results}

\section{How do PTs develop SCK for teaching AP through word problem contexts? \\ Overall performance}

Findings about PTs' knowledge for teaching AP across the three exams are presented in Table 2.

Table 2 demonstrates PTs' knowledge growth over the semester. Given the pretest was conducted after the class had discussed what AP was, most PTs demonstrated sound CCK. In addition, most PTs in the pretest performed well on drawing a diagram to represent the problem. Indeed, the PTs performed well on these two skills across three tests $\left(M_{\mathrm{CCK}}=0.84,0.92\right.$, and 1 across three tests; $M_{\text {diagram }}=0.92,0.92$, and 1 across three tests). The Friedman test indicated no changes over the course of the semester for both CCK and drawing a diagram to represent the word problem.

However, the PTs in the pretest had difficulties generating correct number sentences and providing meaningful explanations (see Table 2). Results from the Friedman test for these two aspects indicated progress was made over the course of the semester, $x^{2}$ sentence $(2, n=25)=25.2$, $p<0.001 ; x^{2}$ explanation $(2, n=25)=19.18, p<0.001$. In addition, the Wilcoxon test was used to compare two

\begin{tabular}{|c|c|c|c|c|c|c|c|}
\hline & & \multicolumn{2}{|c|}{ Pretest } & \multicolumn{2}{|c|}{$\begin{array}{l}\text { Posttest I } \\
\text { (mid-term exam) }\end{array}$} & \multicolumn{2}{|c|}{$\begin{array}{l}\text { Posttest II } \\
\text { (final exam) }\end{array}$} \\
\hline & & M & SD & M & SD & M & SD \\
\hline CCK & What is AP & 0.84 & 0.37 & 0.92 & 0.28 & 1 & 0 \\
\hline \multirow[t]{4}{*}{ SCK } & Drawing a diagram & 0.92 & 0.28 & 0.92 & 0.28 & 1 & 0 \\
\hline & $\begin{array}{l}\text { Correct number } \\
\text { sentences }\end{array}$ & 0.24 & 0.44 & 0.48 & 0.51 & 0.96 & 0.2 \\
\hline & $\begin{array}{l}\text { Meaningful } \\
\text { explanations }\end{array}$ & 0.04 & 0.2 & 0.16 & 0.37 & 0.6 & 0.5 \\
\hline & $\begin{array}{l}\text { Verbal precedence } \\
\text { view }\end{array}$ & 0.04 & 0.2 & 0.16 & 0.37 & 0.28 & 0.46 \\
\hline
\end{tabular}


orthogonal contrasts for each aspect (Leech et al. 2008). The posttest II (final) and posttest I (mid-term) contrast was found to be significant for both aspects: $r_{\text {sentence }}=$ $0.69, r_{\text {explanations }}=0.61$; however, the posttest I (mid-term) and pretest contrast was not significant for either aspect. This suggests that the PTs' difficulties found in the pretests remained in the mid-term exam but changed significantly from the mid-term to the final exam.

With regard to the representational sequence, PTs were expected to possess a verbal precedence view that started with reasoning upon the diagrams. Only one PT demonstrated this view in the pretest. Over time, there was an increased number of PTs who obtained this view ( $n=1,4$, and 7 across three tests; $M_{\text {verbal }}=0.04,0.16$, and 0.28 , respectively). Yet, the Friedman test showed that this change was not significant.

\section{Issues with explanations}

Table 3 presents the results of PTs' explanations for the number sentences they generated in three diagnostic tests. In the pretest, the major difficulties were that PTs (72\%) generated number sentences based on the literal order of the numbers in the problem statement (e.g., 5 , 2 , and 3 , see Table $4 \mathrm{a}, \mathrm{b}$ for examples), and when explaining their number sentences, $76 \%$ of the PTs explained only individual numbers (e.g., 5 mangos, 2 plates, and 3 tables) without considering the meaning of each step (see Table 4a). This confirms the findings of Ding et al. (2013). With instruction, the number sentence mistake decreased in posttest I (32 \%) and disappeared completely in posttest II. Yet, the explanation mistake remained robust in posttest I (72\%) and then decreased in posttest II (24\%). In addition, there were minor issues that seemed to indicate a middle status of PTs' understanding. For instance, some PTs (4\% in pretest, $20 \%$ in posttest I) provided a correct first step but incorrect second step for the number sentence (see Table 4c). With regard to explanations, some PTs provided partial- or pseudo-explanations $(20,12$, and $16 \%$, respectively). These PTs appeared to acknowledge the importance of giving meaning to each step; however, because of the mismatch between their number sentences and the explanations, their explanations were inaccurate (see Table 4b, c).

\section{Issues with representational sequence}

Examination of PTs' representational sequence reveals PTs' lack of verbal precedence view. First, many PTs directly provided their numerical solution even before drawing a diagram (see Tables $4 \mathrm{~b}$ and $5 \mathrm{a}, \mathrm{b}$ ), which indicates a symbol precedence view. Second, there seemed to be a "blending" view that mixed verbal and symbol precedence views. That is, some PTs first drew a diagram to represent the word problem. After that, they wrote a numerical solution, followed by explanations of the diagram (see Tables $4 \mathrm{a}$ and $5 \mathrm{c}, \mathrm{d}$ ). Given the diagram in this situation was not utilized to generate a number sentence, this blending view was in nature symbol precedence, which was termed as "semi-symbol precedence view" in this study. Across the three tests, only a few PTs demonstrated a verbal precedence view (see Tables $4 \mathrm{c}$ and 5e, f). Fig. 4 summarizes the number of PTs who heldeach view across the three tests. While the symbol precedence view decreased ( $n=10,4$, and 2 , respectively) and verbal precedence view increased $(n=1,4$, and 7 , respectively), the semi-symbol precedence view was consistently the most prevalent $(n=14,17$, and 16 , respectively), which may partially explain why many PTs drew sound diagrams yet did not provide solutions that bear contextual inferences.

\section{PTs' voice in prompts}

Consistent with the results in the diagnostic tests, PTs' voice in two prompts indicated their learning and changes. In prompt 1 , PTs self-compared their performance on the string and mango problems and reflected upon their progresses in representations and explanations, which suggested different levels of understanding after the first formal instruction (see Table 6).

As indicated by Table 6, among the 24 PTs (one response missing), 11 of them (45.7\%) stated that they did not have any confusion, which was consistent with the results of the posttest I (mid-term). Four of them (16.7 \%) suggested the need for further practice. Six PTs (25\%) admitted that they were uncertain about how to

Table 3 Issues about the number sentences and explanations

\begin{tabular}{|c|c|c|c|c|c|c|c|}
\hline & \multirow[t]{2}{*}{ Illustrating AP } & \multicolumn{2}{|c|}{ Pretest } & \multicolumn{2}{|c|}{ Posttest I (mid-term exam) } & \multicolumn{2}{|c|}{ Posttest II (final exam) } \\
\hline & & Freq & $\%$ & Freq & $\%$ & Freq & $\%$ \\
\hline \multirow[t]{3}{*}{ Generating number sentences } & Attending to the literal order & 18 & 72 & 8 & 32 & 0 & 0 \\
\hline & Having no meaning in the 2nd step & 1 & 4 & 5 & 20 & 1 & 4 \\
\hline & Correct number sentences & 6 & 24 & 12 & 48 & 24 & 96 \\
\hline \multirow[t]{3}{*}{ Providing explanations } & Explaining numbers only & 19 & 76 & 18 & 72 & 6 & 24 \\
\hline & Partial- or pseudo-explanations & 5 & 20 & 3 & 12 & 4 & 16 \\
\hline & Complete explanations & 1 & 4 & 4 & 16 & 15 & 60 \\
\hline
\end{tabular}


Table 4 Issues of PTs' number sentences and explanations in the pretest

Number sentence: Attending the literal order

generate a number sentence that may refer back to the story situation, and three PTs (12.5\%) expressed frustration about the intended approach and refused to change their existing conceptions. For example, one PT stated, "I don't understand why you have to know exactly what object it refers to. I just think it would confuse kids if it confuses me and I would never teach this way" (see Table 6). After continuous instruction, PTs' responses in prompt 2 uniformly suggested their improved understanding and more positive views. In particular, those PTs who initially had refused to change clearly acknowledged the role of word problem contexts, especially the role of diagrams in developing children's understanding of fundamental mathematical ideas. For instance, one PT stated, "If you draw the word problem out it is much easier for students to understand the concept. The associative property is much easier to understand where you first draw out the picture." Another PT wrote, "I've learned to first draw a picture to help them see the groups because some word problems can be tricky.... I think a picture also let them see how the two problems are equivalent and see the associative property of multiplication as more concrete." In summary, PTs' responses to the three diagnostic tests, along with their voice in the two prompts revealed progress with their remaining difficulties. The next section reports how the methods course instruction played a role in PTs' learning.

\section{How does the methods course instruction play a role in developing PTs' SCK?}

To support PTs' learning, the instructor provided interventions that aimed to enhance PTs' representation uses and explanations. As mentioned in the "Methods" section, this process included an initial formal discussion (lesson 1) incorporating the mango problem to address issues with explanations and representations. After this, two follow-up lessons were provided to continuously address these issues (see Fig. 3). In lesson 2, PTs were asked to create a word problem to illustrate a given arithmetic example of the AP. ${ }^{2}$ In lesson 3 , PTs were asked to create a word problem for the AP and then exchange it with peers for solutions. Across these lessons, PTs demonstrated progress in some aspects but still had difficulties with others.

\section{Addressing explanation issues}

During lesson 1, the instructor handed back the pretest (mango problem) without grading marks and suggested PTs share their work within small groups. Each group then came up with a representative solution for class discussion (see Fig. 5). Among five groups, only one contained correct number sentences, three were incorrect, and one was incomplete. This overall result was consistent with the pretest (see Table 2). Using the work of group 1 that contained a mistake, the instructor led a whole-class discussion of the step-by-step meanings.

\section{Focusing on step-by-step meaning}

One PT in group 1 explained their solution $(5 \times 3) \times 2=$ $5 \times(3 \times 2)$, "You can put 5 , or 2 , or 3 in any order and you can always get the answer."

Instructor (I): Assuming that I am a third grader and don't understand why you did $5 \times 3$, as a teacher, can you help me understand what it means by $5 \times 3$ using your picture? 
Table 5 Examples of symbol, semi-symbol, and verbal precedence views

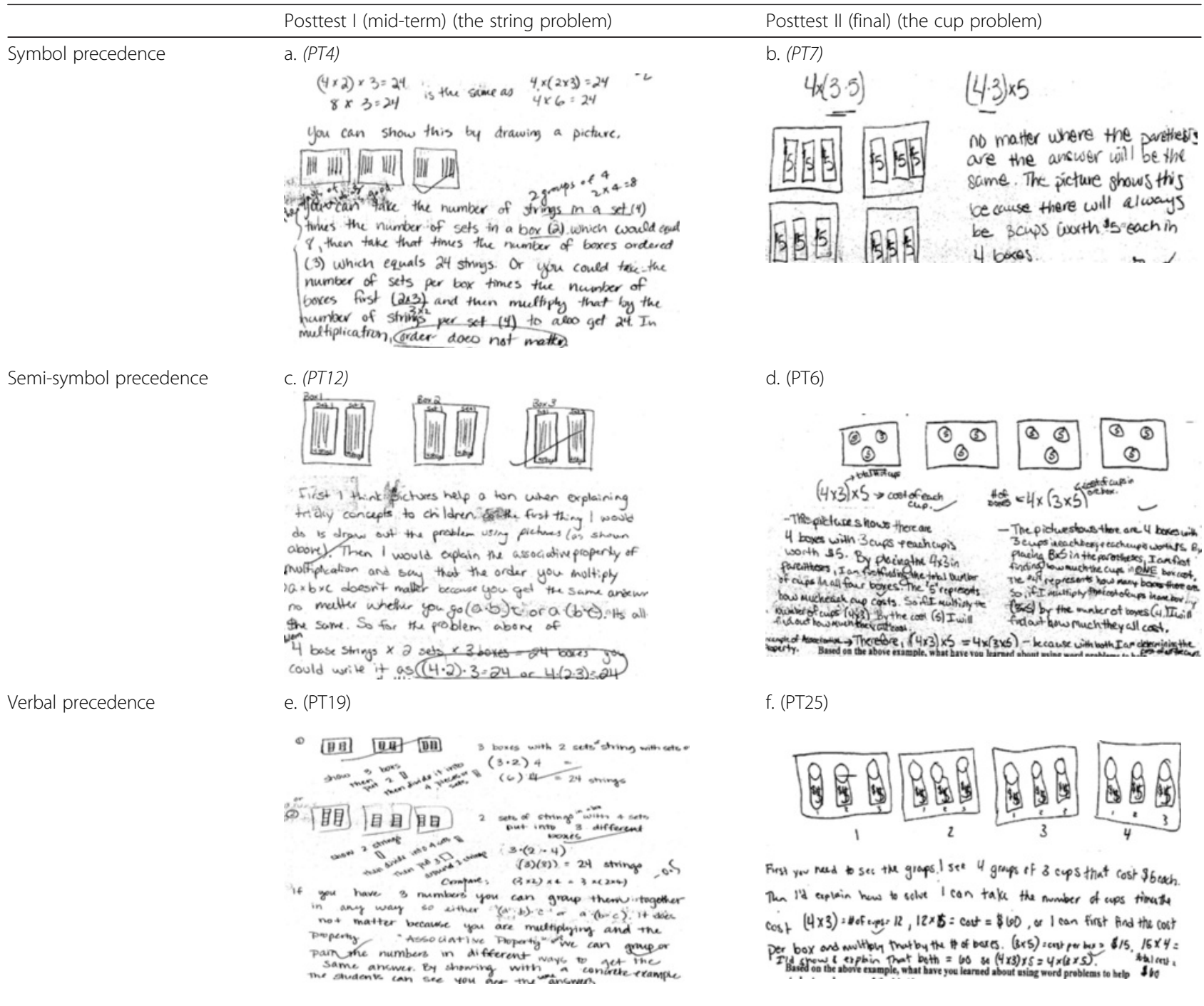

PT2: (from group 1): There are 5 pieces of mango, time 3 tables, equals 15. And we take that to time 2 plates on each table.

PT2's explanation indicates that she attended to the meaning of each number (5 and 3 ) but not the interaction between them $(5 \times 3)$. This is similar to the major issue observed in the pretest. The instructor asked if the other groups were convinced. One PT commented that there were no 5 groups of 3 in the picture, indicating the consideration of the meaning for each step. The instructor then asked whether $5 \times$ 3 had a referent in this problem situation. This led to group 1's self-correction, "So, we actually should do $5 \times 2 \ldots 5$ groups of 2 , oh, 2 groups of 5 so $2 \times 5 \ldots$ " With the back-and-forth discussion of the meaning of the first step, the class reached an agreement that the first step should be $2 \times 5$, which represents 10 mangos on one table.

Surprisingly, PTs' understanding of the first step did not spontaneously transfer to the second step. A few PTs quickly suggested that the next step was to "find 3 tables," "time 3," or " $10 \times 3$." These responses, accepted by the class, did not reflect the problem situation, 3 tables of 10 mangos. This observation confirmed the findings in the diagnostic tests that the PTs could not consistently apply the meaning of multiplication to the second step. To facilitate discussion, the instructor drew PTs' attention back to the diagram:

I: So, here is one table, how many mangoes on each table? 


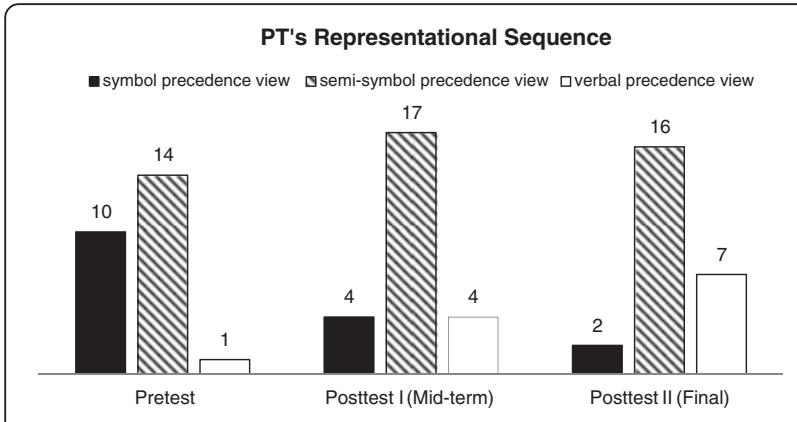

Fig. 4 Number of PTs who demonstrated different views across three diagnostic tests

PTs: 10

I: (labeled a "10" for each table in their picture, see the first picture in Fig. 5) Now, you have how many groups of what?

\section{PTs: 3 groups of 10}

I: So, what would be your number sentence?

PT: $3 \times 10$....It represents 30 mangos in total.

In the above discussion, PTs' attention was consistently oriented to the definition or the basic meaning of multiplication-how many groups of what. Note that even though these class discussions involved PTs who provided correct responses, these discussions seemed not to produce a success in PTs' understanding. One evidence was that at the end of lesson 1, the instructor handed out the actual textbook page of the mango problem (see Fig. 1) and asked the PTs to discuss it. Surprisingly, except for two PTs who commented on the textbook issue with explanations, no one showed any interest for further discussion. Further evidence revealed that only $48 \%$ of the PTs could generate a meaningful number sentence in the mid-term exam (see Table 2). The instructor pondered whether the emphasis on step-by-step meaning in lesson 1 had overwhelmed PTs so that they saw only pieces of information but not the general problem structure.

\section{Focusing on global meaning}

The instructor made an effort to stress the issue with explanations by discussing the global meaning of the twostep problem ("groups of groups of something") so as to back up PTs' understanding with a schema. This took place in lesson 2 after the mid-term exam (April 6), through a chapter titled "Algebraic Thinking" (Reys et al. 2009). Using $(4 \times 3) \times 2=4 \times(3 \times 2)$, the instructor asked the PTs to create word problems to illustrate the AP. One group created a story problem showing "2 groups of $(4 \times 3)$," which has no meaning in the second step. This scenario once again signified a need to build PTs' structural understanding. As such, the instructor provided a whole-group discussion:

I: If we discard the context and only look at this number sentence, what does it mean by $4 \times 3 \times 2$ ?

PT: You have 4 groups of 3 groups of 2.

I: In this equation that shows AP, we have $(4 \times 3) \times 2$ and $4 \times(3 \times 2)$. The first expression indicates 12 groups of 2 , right? (Uniformly agree). For the second expression $4 \times(3 \times 2)$, you have how many groups of what?

PT: 4 groups of 6

I: We can sketch a picture to illustrate this problem structure, 4 groups of 3 groups of 2. You can imagine the picture from outside to the inside, that is, you first see 4 groups, then 3 subgroups in each, and eventually, 2 objects inside each subgroup (The instructor sketched a picture on the board). This picture indicates the structure of the word problem that you will create.

I: Later, when you try to solve your story problem, you may reason upon this picture in two ways, resulting in $(4 \times 3) \times 2$ and $4 \times(3 \times 2)$ that correspond to " 12 groups of 2" and "4 groups of 6" respectively. Do you see 12 groups of 2 ?

PT: Yes! (Confidently)

I: Do you see 4 groups of 6 ?

PT: Yes!!! (Confidently)

In the above episode, the instructor consistently emphasized the definition or basic meaning of multiplication (how many groups of what) but at a global level that targets the hierarchical structure of multiplication. The instruction also contained "shortcuts," viewing a picture from outside to inside and viewing a picture two ways. These discussions seemed to generate a positive outcome by offering the PTs a schema that enabled all groups to create appropriate word problems (e.g., about 4 tables of 2 plates of 3 cookies, 4 flowerpots of 3 tulip of 2 ladybugs, and 4 boxes of 3 vases of 2 flowers). Each group explained their story problems and solutions that together illustrated AP, $(4 \times 3) \times 2=4 \times(3 \times 2)$. The class ended with widespread excitement, indicating the PTs enhanced motivation in learning. This success continued in lesson 3 when PTs created and solved each other's word problems in order to illustrate the AP. 
Table 6 PTs' self-reflection on learning to teach AP in prompt 1

\begin{tabular}{|c|c|c|}
\hline Levels of understanding & Frequency (\%) & Example responses \\
\hline No confusion & $11(45.7)$ & 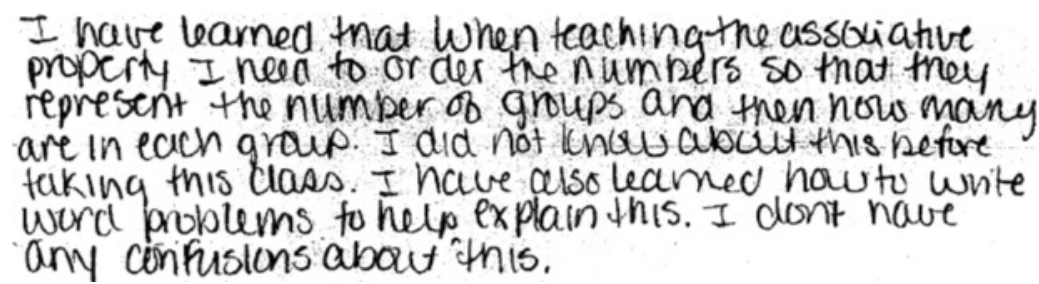 \\
\hline
\end{tabular}

Basically understand and $\quad 4(16.7)$ practice needed

Still have confusion about the "order"

Question this approach and refuse to change
$6(25)$

$3(12.5)$

\begin{abstract}
Knowledge that I have gained for future teaching of fundamental ideas includes the fact that concepts can be made clearer by the use of pictures. Drawing out the situation and clearly identifying the numbers involved and what they stand for may be extremely heloful when teaching students. With question \#4 specifically, I still fixd it difficult to relate the property
being taught directly to the story being taught directly to the story a better understanding of this with more practice.
\end{abstract}

\section{This problem is where I tearned the most-} Inever realized how the associatio problem woiks into these probems, but knaw it do:s.

I undentand for fuiture teaching I reed to indrand te idea clearly betue I even apprach Mystuand about the problem. I am still mat

Well when I learned the associative property wenever used pictures to explain it. We were prsbably tanght the properties in junior high and never used pictures ts show them. I would say that as long as you are using the same three numbers I don't understand Why you have to know exattly what obiect it refers to. I just think it would confuse kids if it contuses me and. I would never teach of this way.
Interestingly, in lesson 3 while PTs were creating story problems, one PT shouted out her surprising findings about the previously discussed mango problem, "So even on this (pointing to the actual textbook page handed out during Lesson 1), it is not right? ... Oh!!! ...Yes, I agree now! We created a problem similar to this. But now I think the textbook, it is wrong!" This response was in sharp contrast to PTs' responses at the end of lesson 1 where most PTs could not recognize the textbook issue with explanations.
Indeed, PTs' improved understanding was confirmed by their performance on the final exam (see Table 2) where $96 \%$ of the PTs generated correct number sentences (as opposed to $48 \%$ on the mid-term exam) and $60 \%$ provided meaningful explanations (as opposed to $16 \%$ on the mid-term exam). It appears that the instruction of global meaning has provided strong support for PTs to generate meaningful number sentences and explicitly explain them. 


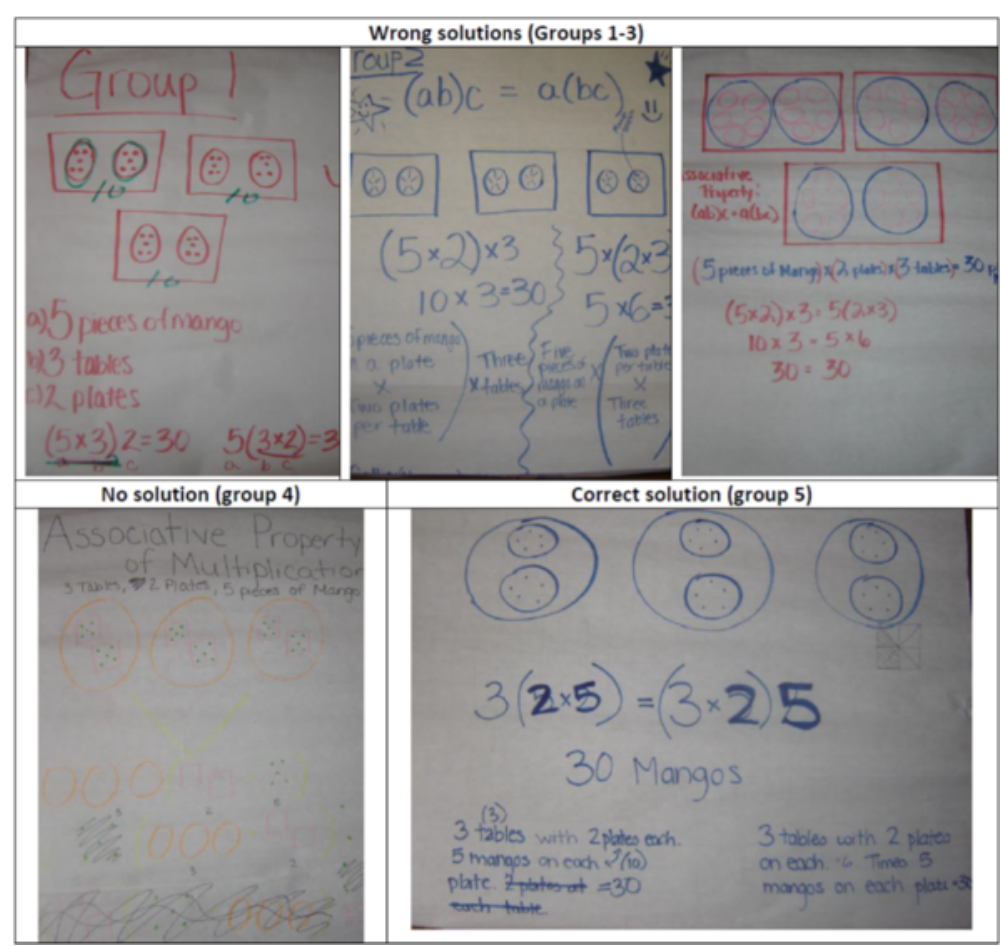

Fig. 5 PTs' group work during the first formal instruction

\section{Addressing representation issues}

In terms of representations, we expect PTs to start with concrete contexts to conduct verbal reasoning (e.g., drawing diagrams and reason upon the problem situation). From there, they should fade concreteness into abstract representations (generate number sentences to reveal AP). This representational sequence, however, did not occur smoothly, likely due to the PTs' symbol precedence review that was hard to overcome.

\section{Challenging PTs' symbol precedence view partially}

In lesson 1, after the discussion of the first solution based on verbal reasoning, the class was asked to figure out the second solution. A PT quickly suggested the second solution based on her knowledge of the AP formula, $(a b)_{c}=a(b c)$ : "Just like to show AP, like we have parentheses, like we can do in different order..." S4's suggestion indicated a symbol precedence view because she came up with the second solution based on her prior abstract knowledge rather than reasoning upon the mango problem. To challenge this unexpected view, the instructor commented:

T: But children don't know AP of multiplication yet, right? That's why you need to teach them and reveal this property through this word problem context.
S4: Ok, so in parenthesis, we have $3 \times 2$, five in the end. 3 tables and 2 plates on each table.

$\mathrm{T}$ : If we teach elementary children, we need to slow down and they need to see what it means by $3 \times 2$. So, do we see 3 groups of 2 ?

S. Yes... it represents the number of plates.

In this episode, the instructor's first suggestion, "reveal this property through this word problem context," demanded verbal reasoning. However, this was not understood by the PT as a challenge to her thinking. Rather, she continued with symbolic reasoning, which, however, was not criticized by the instructor who asked only for an explanation of those symbols. As such, the challenge to PT's symbol precedence view did not reach its potential. It should be noted that the instructor did purposely record the class conversation on the board in the sequence of represent-solve-compare-reveal (see Fig. 2) and guided the class to look back at this general teaching approach, which implicitly lined up with a verbal precedence view.

\section{Reinforcing PTs' symbol precedence view unintentionally}

Even though verbal precedence view was an expectation from the PTs, course instruction unintentionally reinforced 
the symbol precedence view. In the second lesson, the PTs were asked to create a story problem to illustrate $(4 \times 3) \times$ $2=4 \times(3 \times 2)$. Once an appropriate word problem is created, they should reason upon the word problem inductively to illustrate the AP. However, during the class discussion of the global meaning of $4 \times 3 \times 2$, the instructor introduced a shortcut of visualizing 4 groups of 3 groups of 2 from outside to inside, which was quickly taken by the PTs as a crutch for problem solving. This observation was most apparent in lesson 3 where the PTs were asked to solve peers' word problems to illustrate AP. Instead of reasoning upon the word problems, some PTs immediately generated a number sentence like $2 \times 6 \times 3$ by viewing the picture in a particular order (from outside to inside). From there, they added parentheses based on their knowledge of AP and explained the meaning of each step of these solutions. The above sequence reflected the semi-symbol precedence view, which was further seen on the final exam. For instance, a few PTs wrote, "from outside to inside" on the final exam and PT5's explanation was procedural, "First we have 4 boxes so boxes is our largest so it comes first; Second, we have 3 cups in each box, so that comes next; Finally, each cup cost $\$ 5$ that is our smallest amount." Such explanations did not make meaningful reasoning based on the word problem situations, which may have explained why only $60 \%$ of the PTs in the final exam could provide complete explanations (see Table 3) and why the verbal precedence view did not increase as expected on the final exam (see Table 2).

\section{Discussion}

Developing PTs' SCK is an important and much needed area of research, which has been regarded as challenging (Morris et al. 2009; Suzuka et al. 2010). How to support PTs' growth in such knowledge has been rarely studied. In particular with developing PTs' SCK for teaching fundamental mathematical ideas, there are very few studies that have reported such effort in mathematics courses. The present study, by carefully documenting the successes and challenges in developing PTs' SCK, contributes to the existing literature. For instance, while Ding et al. (2013) reported that PTs lack CCK and SCK when they first enter education program, our findings indicate that it is relatively easy to develop PTs' CCK but challenging to develop their SCK. This might be due to the fact that SCK is a new form of knowledge that requires a new mode of thinking. In particular, this study has focused on two SCK components, explanations and representations (Ball et al. 2008). We have obtained greater success in supporting PTs' meaningful explanations but less success in representational sequence, likely due to PTs' robust symbol precedence view. Even though we only have studied two SCK components, our findings shed light on the mathematics education field because the work of building a knowledge base calls for small tests for small changes (Morris and Hiebert 2009).

\section{Developing PTs' explanation skills: the importance of stressing basic meanings}

In this study, one SCK-related difficulty seen in the PTs involved explaining the meaning of number sentences when referring back to the concrete story situations. Some PTs tended to focus on the individual quantities rather than the interactions between them. Others cannot consistently apply the definition or the basic meaning of multiplication across two steps for quantitative reasoning. Such levels of understanding may lead to missing opportunities for deep initial learning with their future students (Chi and VanLehn 2012; Richland et al. 2012). In this sense, the current study adds to Ding et al. (2013) by highlighting the directions that teacher education courses may take when developing PT's SCK.

When the methods course is designed to deliberately address PTs' difficulties in explanations, PTs can grow their SCK as indicated by the diagnostic tests. We acknowledge the possibility that the consecutive testing on similar tasks might have contributed to PTs' performance; however, it should also be noted that the assessment task in the posttest II (final exam) was indeed more complex than the previous tasks. The success in developing PTs' explanations may be partially attributed to the instructor's consistent emphasis on the definition or the basic meaning of multiplication. For instance, the instructor kept asking for the meaning of each step, "how many groups of what?" and stressed the mapping process between number sentences and diagrams. This finding echoes Beckmann et al. (2015) where preservice middle school teachers succeed in proportional reasoning lessons due to the instructors' consistent emphasis of the definition of multiplication. As these researchers suggested, consistent and explicit use of the definition of multiplication can support the development of teachers' proficiency with quantitative reasoning, which may further provide a basis for PTs to unpack mathematical tasks in ways that prompt students' mathematical reasoning and explanations. This adds to the literature of SCK as it illuminates a detailed path to support PTs' explanations of mathematical ideas (Ball et al. 2008).

It should be noted that PTs' development of explanation skills was gradual. In this study, the development process involved different formats of instructional support ranging from stressing the step-by-step meaning to the global meaning. To stress the step-by-step meaning, the instructor asked PTs to reason upon the concrete story situation to write each step based on the basic meaning of multiplication ("a groups of b" is represented as $a \times b)$. The two solutions were then compared to generate an instance of AP. This bottom-up approach 
indicates deductive reasoning. In contrast, to stress the global meaning, the instructor first helped students understand the meaning of a two-step multiplication $a \times b \times c$, which represents $a$ groups of $b$ groups of $c$. This was further mapped to two solutions $(a \times b)$ groups of $c$, and $a$ groups of $(b \times c)$, and each step of the two solutions was further referred back to the story situation. This top-down approach indicates deductive reasoning. With this instructional effort, the major issues (attending to the literal order, explaining numbers only) decreased and the expected explanations increased. However, there still exists a middle status (e.g., having no meaning in the second step, pseudo- or partial explanations). This indicates that PTs' SCK development is not an all-ornothing phenomenon. Given that PTs generally possessed weak knowledge when they enter education program (Borko et al. 1992; Simon and Blume 1994; Morris and Hiebert 2009), it takes time to shift their attention from surface to deep explanations. Future studies may explore this interesting middle status phenomenon and seek better ways to promote greater success.

\section{Developing PTs' representation skills: tension between PTs' and children's learning}

To support elementary students' learning, within classrooms, PTs should be able to move flexibly between concrete and abstract representations in responsive ways (National Mathematics Advisory Panel 2008; Pashler et al. 2007). In this study, given that the initial learning of a fundamental mathematical idea is situated in a word problem context, we expect PTs to develop a particular type of SCK skill, reasoning from concrete to abstract, which is well supported by the literature (Goldstone and Son 2005; McNeil and Fyfe 2012; Pashler et al. 2007). However, the PTs demonstrated difficulties in using this intended representational sequence. This may reflect PTs' challenge in linking representations to the underlying ideas or making connections between different representations. As indicated by Table 2, even though the classroom instruction has helped the PTs understand such connections, PTs who were good at drawing a diagram from the beginning did not see the connections among diagram, number sentences, and the corresponding explanations. Another interpretation of the representational difficulties may be attributed to PTs' robust symbol precedence view, which may have hindered PTs' representational uses. As observed from this study, some PTs tended to operate directly on the given numbers of a word problem without reasoning upon the word problem situation or without drawing a diagram. This finding echoes prior studies where US secondary school teachers were found to possess a symbol precedence view because they believed that symbol manipulation is easier than word problems and thus should come before verbal reasoning (Nathan et al. 2002; Nathan and Koedinger 2000). Our finding suggests that elementary preservice teachers hold the same view, which is likely related to PTs' existing compressed knowledge. This interpretation is supported by prior studies suggesting that PTs are often familiar with computation procedures but lack the ability to illustrate, explain, or unpack them (Borko et al. 1992; Morris et al. 2009; Simon and Blume 1994). More interestingly, our emerged findings on PTs' semi-symbolic review contribute to new insights in the literature. As reported, some PTs did draw diagrams to represent the word problem situation; yet, they did not actually use the diagrams to generate number sentences. Still, some PTs used the diagram to generate number sentences but in procedural ways, such as looking at a picture from outside to inside to determine the number orders. In both occasions, diagrams of the given word problem were not utilized to support mathematical reasoning and explanations, which distinguishes the semi-symbol precedence view from the verbal precedence view. The detour from verbal to symbol reasoning further indicates the robustness of PTs' symbol precedence view that may even occur in a single word problem context involving diagrams. Given that prior studies only reported the symbol precedence view with a full lesson or a textbook series (Nathan et al. 2002; Koedinger and Nathan 2004) but not a concrete context that has apparent verbal advantages, our study calls for greater attention to PTs' use of concrete representations. Instead of "whether" concrete representations (e.g., drawing diagrams) are involved in teaching, we should focus on "how" the concrete aids are actually used in ways to support symbolic reasoning.

PTs' robust symbol precedence view presents great challenges for methods courses that aim to develop SCK. University instruction usually starts with PTs' existing concepts that are stored in compressed formats, making the instructional sequence deductive (from abstract to concrete). This sequence is opposite to elementary students' learning process (inductive, from concrete to abstract). The tension between PTs' and children's learning demands a paradigm shift of PTs' existing views, which may cause frustration with some PTs who may question this approach (Suzuka et al. 2010) or give up easily (Borko et al. 1992). Other PTs may revert to their old habits. For instance, when the course instructor provided a shortcut to help PTs visualize the problem structure so as to create a story problem, PTs quickly took it as a crutch for solving the problem based on their compressed knowledge of AP. This, however, conflicts children's learning because children often do not have any prior knowledge of the AP. These findings join the literature on expert blindspots (Nathan and Koedinger 2000), suggesting PTs may simply assume children see what they see. These findings also suggest the complexity 
in developing PTs' SCK due to the tension between PTs' compressed knowledge and children's learning process.

In retrospect, the above tension between PTs' and children's learning may be reduced by improving the methods course instruction. First, the instructor could have acknowledged the tension between PTs' and elementary children's learning, but still explicitly emphasized the importance of reasoning upon a word problem situation from the perspective of children. Helping PTs explicitly see the value of the intended instructional approach may motivate them to struggle for success (Eccles et al. 1983). Second, the instructor could have helped PTs develop a stronger understanding of the definition or the basic meaning of multiplication before offering the shortcuts. With a stronger understanding, PTs may find it easier to conduct mathematical reasoning (Beckmann et al. 2015). In fact, the shortcut may not even be needed during the process of problem solving. This may minimize the risk of reinforcing PTs' procedural foci and symbol precedence view that contradict children's learning.

\section{The role of elementary textbooks in developing PTs' SCK} Findings from this study suggest that incorporating discussions of elementary textbook tasks may serve as an effective path to developing PTs' SCK. This is aligned with research assertions that textbooks should serve as educative materials (Ball 1996; Davis and Krajcik 2005). In this study, the textbook presentation of the mango problem contained similar mistakes as those of the PTs. It is predicted that if PTs have never been exposed to critical discussions like the one in this study, they may teach future students in the same way as the textbook does. As Nathan et al. (2002) pointed out, questionable textbook presentations "can go unchecked and can be implemented throughout the educational system, to the potential detriment of students and teachers" (p. 18). As seen from this study, the in-depth discussion of the mango task as a source problem has served as a worked example of a general teaching approach, which has enabled PTs' various degrees of transfer of the learned SCK.

How and to what extent elementary textbooks support PTs' learning, however, is not straightforward. It seems that there is an interaction between textbook presentation and PTs' own knowledge. When PTs do not possess sophisticated understanding of the intended approach, the issues of textbook presentation are unlikely identified and thus not critically analyzed. This was evident by the PTs' silence at the end of the first lesson when they were invited to comment publically on the textbook presentation. Possibly, when PTs themselves were striving for understanding of the new approach, asking them to analyze a problematic textbook page would increase their work-load. This may explain why many PTs did not acknowledge the textbook issues in a cognitively comfortable manner. In contrast, when equipped with the necessary knowledge, some PTs could spontaneously capture the textbook issue and learn from it. This was evident in lesson 3.

\section{Conclusions}

There are a few limitations of this study. First of all, it involves a small group of PTs $(N=25)$. As such, findings should not be over-generalized. In addition, this study only explores PTs' course work without investigating the field experiences; therefore, it is not clear how PTs may actually transform learned knowledge into classroom settings. Furthermore, this study has a narrowed focus because it mainly involves representations and explanations, whereas the SCK skills may demand other skills such as having ready strategies to respond to common mistakes (Ball et al. 2008). Indeed, the teaching of fundamental mathematical ideas does not necessarily involve word problems (e.g., a volume model is an alternative candidate for teaching AP, National Research Council 2001). Nevertheless, our findings have several implications for teacher education.

First, PTs' SCK acquisition appears to be gradual and takes time, which aligns with the literature assertion of spaced learning (Pashler et al. 2007). This brings a challenge to teacher education. While the current study targets only one fundamental idea, a methods course usually covers many more mathematical topics and thus has limited opportunities to revisit them. A possible solution to this challenge is to set up course goals centering on the teaching of fundamental mathematical ideas that transcend across various contexts. Second, because PTs lacked the ability and habit to explain quantitative relationships based on concrete contexts, this study has identified PTs' robust symbol precedence view. Teacher education programs need to be aware that activities involving word problems and diagrams do not guarantee PTs' sound use of those verbal and visual contexts. Teacher education programs should explicitly challenge PTs' symbol precedence view and stress the importance of quantitative reasoning, which may enable PTs to understand why they should construct a verbal precedence view; however, simply conveying general instructional principles, such as grounding abstract ideas in concrete contexts, may still be ineffective. Methods course instructors should encourage PTs to experience "productive struggles" (Richland et al. 2012, p. 196) without giving out shortcuts too quickly. Finally, this study incorporated elementary textbook pages that contained mistakes as methods course materials. It is clear that these mistakes may not be recognized by PTs without discussion. As such, it is critical for textbook authors to enhance their textbook presentations to better support teacher learning. On the other hand, methods courses could use flawed textbook tasks as counter-examples for course discussion. Future studies 
may explore when, how, and under what circumstances the different types of elementary textbook examples (correct and flawed) may be utilized to support PTs' learning. With continuous research on the ways to overcome PTs' misconceptions and prior views, future elementary teachers can be better equipped with the necessary SCK to teach fundamental mathematical ideas, which in turn may enhance children's learning.

\section{Endnotes}

${ }^{1}$ There is no agreement on the meaning of multiplication. Some define $3 \times 2$ as 3 groups of $2(2+2+2)$ while the others define it as 2 groups of $3(3+3)$. This debate goes beyond the scope of this study. Regardless of the differences, we and other researchers (e.g., Beckmann and colleagues) argue that in order to facilitate students' mathematical reasoning, the definition of multiplication should be applied consistently. The textbooks involved in this study initially defines $3 \times 2$ as 3 groups of 2 .

${ }^{2}$ The PTs in lesson 2 were asked to illustrate the AP, $\mathrm{CP}$, and DP by creating story problems or drawing pictures or using manipulatives. It was found that they had an easy time illustrating both $\mathrm{CP}$ of addition $a+b=b+a$ and the AP of addition $(a+b)+c=a+(b+c)$. For the properties that involve multiplication, the PTs were able to illustrate the CP of multiplication $(a \times b=b \times a)$ when they were reminded about the basic meaning of multiplication and the array model. For the DP $(a+b) \times c=a c+$ $b c$, when PTs were reminded about the basic meaning of multiplication, they were also able to create story problems along with pictures to illustrate this property. However, the AP of multiplication $(a \times b) \times c=a \times(b \times c)$ appeared to be most challenging for PTs, likely due to the fact that this property involves two steps of multiplication.

\section{Competing interests}

The author declares that she has no competing interests.

\section{Acknowledgements}

This study is partially supported by the National Science Foundation CAREER program under Grant No. DRL-1350068 at Temple University. Any opinions, findings, and conclusions in this study are those of the author and do not necessarily reflect the views of the National Science Foundation. The author is grateful to the editor and the three anonymous reviewers for their constructive feedback. Thanks also go to Ryan Hassler for editorial assistance.

Received: 27 January 2016 Accepted: 25 April 2016

Published online: 10 May 2016

\section{References}

Ball, DL (1996). Teacher learning and the mathematics reforms: what we think we know and what we need to learn. Phi Delta Kappan, 77, 500-508.

Ball, DL, Thames, MH, \& Phelps, G (2008). Content knowledge for teaching: what makes it special? Journal of Teacher Education, 59, 389-407.

Beckmann, S, \& Izsák, A (2015). Two perspectives on proportional relationships: extending complementary origins of multiplication in terms of quantities. Journal for Research in Mathematics Education, 46, 17-38.

Beckmann, S, Izsák, A, \& Ölmert, i. B. (2015). From multiplication to proportional relationships. In X. Sun, B. Kaur, \& J. Novotná (Eds.), Conference proceedings of
ICMI study 23: primary mathematics study on whole numbers (pp. 518-525). Macau: University of Macau.

Borko, H, Eisenhart, M, Brown, CA, Underhill, RG, Jones, D, \& Agard, PC (1992). Learning to teach hard mathematics: do novice teachers and their instructors give up too easily? Journal for Research in Mathematics Education, 23, 194-222.

Bruner, JS (1960). The process of education. Cambridge: Harvard University Press. Carpenter, TP, Franke, ML, \& Levi, L (2003). Thinking mathematically: integrating arithmetic \& algebra in elementary school. Portsmouth: Heinemann.

Chi, MTH, \& VanLehn, KA (2012). Seeing deep structure from the interactions of surface features. Educational Psychologist, 47(3), 177-188.

Chi, MTH, de Leeuw, N, Chiu, M, \& LaVancher, C (1994). Eliciting self-explanations improves understanding. Cognitive Science, 18, 439-477.

Cobb, P (1994). Where is the mind? Constructivist and sociocultural perspectives on mathematical development. Educational Researcher, 23(7), 13-20.

Common Core State Standards Initiative (2010). Common core state standards for mathematics. Retrieved from http://www.corestandards.org/Math/. Accessed 1 May 2013.

Davis, EA, \& Krajcik, J (2005). Designing educative curriculum materials to promote teacher learning. Educational Researcher, 34(3), 3-14.

Ding, M, \& Carlson, MA (2013). Elementary teachers' learning to construct high quality mathematics lesson plans: a use of IES recommendations. The Elementary School Journal, 113, 359-385.

Ding, M, Li, X, Capraro, MM, \& Capraro, RM (2012). Supporting meaningful initial learning of the associative property: cross-cultural differences in textbook presentations. International Journal for Studies in Mathematics Education, 5(1), 114-130.

Ding, M, Li, X, \& Capraro, M (2013). Preservice elementary teachers' knowledge for teaching the associative property: a preliminary analysis. Journal of Mathematical Behavior, 32, 36-52.

Eccles, JS, Adler, TF, Futterman, R, Goff, SB, Kaczala, CM, Meece, JL, \& Midgley, C (1983). Expectancies, values, and academic behaviors. In J. T. Spence (Ed.), Achievement and achievement motivation (pp. 75-146). San Francisco: W. H. Freeman.

Gerofsky, S (2009). Genre, simulacra, impossible exchange, and the real: How postmodern theory problematises word problems. In L. Verschaffel, B. Greer, \& W. V. Dooren (Eds.), Words and worlds: Modeling verbal descriptions of situations (pp. 21-38). Rotterdam: The sense publisher.

Goldstone, RL, \& Son, JY (2005). The transfer of scientific principles using concrete and idealized simulations. The Journal of the Learning Sciences, 14, 69-110.

Greenes, C, Larson, M, Leiva, MA, Shaw, JM, Stiff, L., Vogeli, BR, \& Yeatts, K (2005). Houghton Mifflin. Boston: Houghton Mifflin Company.

Hiebert, J, Carpenter, TP, Fennema, E, Fuson, KC, Wearne, D, Murray, H, et al. (1997). Making sense: teaching and learning mathematics with understanding. Portsmouth: Heinemann.

Kaminski, JA, Sloutsky, VM, \& Heckler, AF (2008). The advantage of abstract examples in learning math. Science, 320, 454-455.

Kaput, JJ, Carraher, DW, \& Blanton, ML (Eds.). (2008). Algebra in the early grades. New York: Lawrence Erlbaum Associates.

Koedinger, KR, \& Nathan, MJ (2004). The real story behind story problems: effects of representations on quantitative reasoning. Journal of the Leaning Sciences, 13, 129-164.

Larkin, JH, \& Simon, HA (1987). Why is a diagram is (sometimes) worth ten thousand words. Cognitive Science, 11, 65-100.

Larsen, S (2010). Struggling to disentangle the associative and commutative properties. For the Learning of Mathematics, 30(1), 37-42.

Leech, NL, Barrett, KC, \& Morgan, GA (2008). SPSS for intermediate statistics: use and interpretation (3rd ed.). New York: Erlbaum.

Lewis, C (1988). Why and how to learn why: analysis-based generalization of procedures. Cognitive Science, 12, 211-256.

Lloyd, GM, \& Behm, SL (2005). Preservice elementary teachers' analysis of mathematics instructional materials. Action in Teacher Education, 26(4), 48-62.

McNeil, NM, \& Fyfe, ER (2012). "Concreteness fading" promotes transfer of mathematical knowledge. Learning and Instruction, 22, 440-448.

Morris, A, \& Hiebert, J (2009). Introduction: building knowledge bases and improving systems of practice. Elementary School Journal, 109, 429-441.

Morris, A, Heibert, J, \& Spitzer, S (2009). Mathematical knowledge for teaching in planning and evaluating instruction: what can preservice teachers learn? Journal for Research in Mathematics Education, 2009(40), 491-529. 
Nathan, MJ, \& Koedinger, KR (2000). An investigation of teachers' beliefs of students' algebra development. Cognition and Instruction, 18, 209-237.

Nathan, MJ, Long, SD, \& Alibali, MW (2002). The symbol precedence view of mathematical development: a corpus analysis of the rhetorical structure of textbook. Discourse Processes, 33, 1-12.

National Mathematics Advisory Panel. (2008). Foundations for success: The final report of the National Mathematics Advisory Panel. Washington: U.S. Department of Education.

National Research Council. (2001). Adding it up: helping children learn mathematics. Washington: National Academy Press.

Nussbaum, EM (2014). Categorical and nonparametric data analysis: choosing the best statistical technique. New York: Taylor \& Francis.

Pashler, H, Bain, PM, Bottge, BA, Graesser, A, Koedinger, K, McGaniel, M, et al. (2007). Organizing instruction and study to improve student learning (NCER 2007-2004). Washington: National Center for Education Research.

Reys, RE, Lindquist, MM, Lambdin, DV, \& Smith, N (2009). Helping children learn mathematics (9th ed.). Hoboken: John Wiley \& Sons.

Richland, LE, Stigler, JW, \& Holyoak, KJ (2012). Teaching the conceptual structure of mathematics. Educational Psychologist, 47, 189-203.

Schwartz, JE (2008). Elementary mathematics pedagogical content knowledge: powerful ideas for teachers. Boston: Allyn \& Bacon.

Simon, MA, \& Blume, GW (1994). Building and understanding multiplicative relationships: a study of prospective elementary teachers. Journal for Research in Mathematics Education, 25, 472-494.

Stake, RE (1995). The art of case study research. Thousand Oaks: Sage.

Suzuka, K, Sleep, L, Ball, DL, Bass, H, Lewis, JM, \& Thames, M (2010). Designing and using tasks to teach mathematical knowledge for teaching. Association of Mathematics Teacher Educators, Monograph, 4, 7-23.

Venkat, $H$ (2015). Representational approaches to primary teacher development in South Africa. In X. Sun, B. Kaur, \& J. Novotná (Eds.). Conference proceeding of ICMI study 23: Primary mathematics study on whole numbers (pp. 583-588). Macau, China: University of Macau.

\section{Submit your manuscript to a SpringerOpen ${ }^{\circ}$ journal and benefit from:}

- Convenient online submission

- Rigorous peer review

Immediate publication on acceptance

- Open access: articles freely available online

- High visibility within the field

- Retaining the copyright to your article

Submit your next manuscript at $\gg$ springeropen.com 